\title{
Suggestive Evidence for Linkage of Schizophrenia to Markers at Chromosome 15q13-14 in Taiwanese Families
}

\author{
Chih-Min Liu, ${ }^{1}$ Hai-Gwo Hwu, ${ }^{1 *}$ Ming-Wei Lin, ${ }^{2}$ Wen-Chen Ou-Yang, ${ }^{3,4}$ Sandy F.-C. Lee, ${ }^{5}$ \\ Cathy S.J. Fann, ${ }^{6}$ Su-Hsien Wong, ${ }^{1}$ and Shu-Hua Hsieh ${ }^{1}$ \\ ${ }^{1}$ Department of Psychiatry, College of Medicine, National Taiwan University Hospital, Taipei, Taiwan \\ ${ }^{2}$ Department of Medical Research and Education, Veterans General Hospital, Taipei, Taiwan \\ ${ }^{3}$ Chianan Psychiatric Center, Department of Health, Tainan, Taiwan \\ ${ }^{4}$ Institute of Public Health, National Yang-Ming University, Tapei, Taiwan \\ ${ }^{5}$ Taoyuan Psychiatric Center, Taoyuan, Taiwan \\ ${ }^{6}$ Institute of Biomedical Science, Academia Sinica, Taipei, Taiwan
}

In order to evaluate the linkage of schizophrenia to loci at chromosome 15q, we genotyped six microsatellite markers at chromosome 15q11-14 in 52 Taiwanese schizophrenic families. Two phenotype models (narrow: DSM-IV schizophrenia only; and broad: including schizophrenia, schizoaffective, and other nonaffective psychotic disorders) were used to define the disease phenotype. Maximum nonparametric linkage scores (NPL scores) of $3.33(P=0.0003)$ and $2.96(P=0.0008)$ were obtained at the marker D15S976 under broad and narrow models, respectively. Positive linkage results were also observed at the marker D15S1360, previously reported to have significant linkage to a neurophysiological deficit of schizophrenia, with NPL scores of $2.71(P=0.003)$ and $2.78(P=0.002)$ under broad and narrow models, respectively. The results provide suggestive linkage evidence of schizophrenia to loci at chromo-

Grant sponsor: The National Health Research Institute; Grant number: DOH83, 84, 85, 86, 87, 88-HR-306, NHRI-GT-EX89, 90 P825P, NHRI-EX90-8825PP; Grant sponsor: The National Taiwan University Hospital; Grant number: NTUH-88-A0015, NTUH-89S1505; Grant sponsor: National Science Council, Taiwan; Grant number: NSC-83-0412-B-170-MO2.

*Correspondence to: Dr. Hai-Gwo Hwu, Department of Psychiatry, National Taiwan University Hospital, College of Medicine, No. 7, Chun-Shan South Road, Taipei, Taiwan 100.

E-mail: haigohwu@ha.mc.ntu.edu.tw

Received 23 February 2001; Accepted 23 February 2001

DOI 10.1002/ajmg.1547 some 15q13-14 in an ethnically distinct Taiwanese sample. ๑ 2001 Wiley-Liss, Inc.

KEY WORDS: $\begin{aligned} & \text { schizophrenia; linkage; } \\ & \text { chromosome 15q }\end{aligned}$

\section{INTRODUCTION}

A recent report using a neurophysiological deficit, decrease of P50 inhibition, as the phenotype for linkage analysis found a chromosome 15q14 locus as the site of a possible susceptibility gene for schizophrenia. The genomewide linkage analysis of the P50 inhibition deficit in nine multiplex schizophrenia families found a significant LOD score $(\mathrm{Z}=5.30 ; \theta=0)$ at $\mathrm{D} 15 \mathrm{~S} 1360$ on chromosome 15q14 within $120 \mathrm{~kb}$ of the first exon of the $\alpha-7$ nicotinic receptor subunit gene (CHRNA7). When the clinical diagnosis of schizophrenia was used as the affected phenotype, the maximum LOD score at the same marker was not statistically significant $(\mathrm{Z}=1.33$; $\theta=0.07$ ) [Freedman et al., 1997].

Attempts to replicate this finding showed inconsistent results [Kaufmann et al., 1998; Leonard et al., 1998; Neves-Pereira et al., 1998; Curtis et al., 1999; Riley et al., 2000]. However, three studies showed positive results in Caucasian families [Leonard et al., 1998], in African American families [Kaufmann et al., 1998; Leonard et al., 1998], and in Southern African Bantu families [Riley et al., 2000]. The chromosome region of interest revealed by the initial study harbors the $\alpha-7$ nicotinic receptor subunit gene, which is a theoretically important psychophysiological trait for schizophrenia [Leonard et al., 1996]. It is meaningful to investigate whether the positive linkage findings can be replicated in another distinct ethnic group. Therefore, we used families of Taiwanese schizophrenic probands with at least two affected siblings in an attempt to replicate these findings. 


\section{MATERIALS AND METHODS}

\section{Subjects}

Schizophrenic probands who had at least two affected siblings were identified from the Department of Psychiatry, National Taiwan University Hospital, and the university-affiliated Taoyuan Psychiatric Center. Data collection was initiated after informed consents were obtained from the identified study subjects and their families. All of the family members were personally interviewed by the research psychiatrists using the Psychiatrist Diagnostic Assessment (PDA) [Hwu and Yang, 1987; Hwu, 1999]. The final diagnostic assessment was formulated by integrating the PDA data and clinical information of medical chart records. DSM-IV criteria [American Psychiatric Association, 1994] were used for final diagnoses of schizophrenia, schizoaffective disorder, and other nonaffective psychotic disorders.

The sample comprised 52 nuclear families with at least two affected siblings. One of the affected sibling subjects was married and had an affected son. A total of 242 subjects were recruited, of which 109 members were diagnosed as schizophrenia, 4 members as schizoaffective disorder, and 4 as other nonaffective psychotic disorder. Among the siblings of these 52 families, there were 4 affected triplets and 45 affected pairs and a total of 53 independent sibling pairs under the narrow phenotype model; there were 6 affected triplets and 46 affected pairs and a total of 58 independent sibling pairs under the broad phenotype model. Table I shows the number of siblings (including the affected siblings) and parents with DNA available. The affected subjects were $60 \%$ male and were $32 \pm 0.8$ years of age. The mean age of onset was $21.6 \pm 6.1$ years of age. The unaffected subjects were $52 \%$ male and were $49.1 \pm 1.8$ years of age.

\section{Genotyping}

Six microsatellite markers located in the chromosome 15q11-14 region were genotyped. These markers were distributed across a $7.58 \mathrm{cM}$ genetic distance. The intermarker distance was determined from the Location Database (LDB: http//cedar.genetics.soton. ac.uk/public_html/) and a previous report [Riley et al., 2000].

DNA was extracted from whole blood using a modified salting-out method [Lahiri et al., 1992]. The microsatellite markers were amplified using standard

TABLE I. Distribution of Families by Number of Siblings and Parents Genotyped

\begin{tabular}{lrrr}
\hline \multirow{2}{*}{$\begin{array}{l}\text { Siblings } \\
\text { genotyped }\end{array}$} & \multicolumn{2}{c}{ Parents genotyped } & \\
\cline { 2 - 3 } & 1 & 2 & Total \\
\hline 2 & 5 & 6 & 11 \\
3 & 9 & 25 & 34 \\
4 & 4 & 1 & 5 \\
5 & 0 & 2 & 2 \\
Total & 18 & 34 & \\
\hline
\end{tabular}

PCR condition and $10 \mathrm{ng}$ of genomic DNA with fluorescent $5^{\prime}$ end labeling of the primers. The allele types of these markers were determined by analysis with Genescan software by comparing the fragment sizes with an internal standard in an ABI-377 genetic analyzer (Perkin-Elmer). Genotypes were read independently by two individuals blind to the clinical status of the study subjects.

\section{Statistical Analyses}

The phenotypes of the study samples were assigned to the narrow phenotype model, containing DSM-IV schizophrenia only, and the broad phenotype model, composed of DSM-IV schizophrenia, schizoaffective disorder, and other nonaffective psychotic disorders (including schizophreniform disorder, delusional disorder, and psychotic disorder not otherwise specified).

Two-point linkage analysis was performed using MLINK program of LINKAGE (FASTLINK version 3.0) [Lathrop et al., 1984; Cottingham et al., 1993]. Multipoint parametric LOD score and nonparametric linkage analyses were calculated using GENEHUNTER (version 2.0) [Kruglyak et al., 1996]. In the parametric analyses, the parameters of genetic models used for linkage analyses were as follows. Allelic frequencies were calculated from 86 founders in these study pedigrees. The disease gene frequencies in the dominant and recessive models were 0.005 and 0.1 , respectively. In both the narrow/dominant model and the narrow/recessive model, the penetrance was 0.5 and the probability of phenocopy was 0.005 . The penetrance and the probability of phenocopies were 0.7 and 0.01 , respectively, in both the broad/dominant and the broad/recessive models.

\section{RESULTS}

Two-point LOD score analysis showed a maximum LOD score of $0.8(\theta=0.2)$ at D15S976 under the narrow/ recessive model. Multipoint LOD score analysis showed heterogeneity LOD scores under different phenotype and inheritance model were not more than one at the six markers (data not shown). Nonparametric linkage analysis found suggestive linkage evidence for D15S976 ( $\mathrm{Z}=3.33, P=0.0003$ under the broad model; $\mathrm{Z}=2.96, P=0.0008$ under the narrow model). The flanking marker D15S1360 also showed positive results $(\mathrm{Z}=2.71, P=0.003 ; \mathrm{Z}=2.78, P=0.002$ under broad and narrow model, respectively) as did D15S165 $(\mathrm{Z}=2.5, \quad P=0.005 ; \mathrm{Z}=1.97, P=0.018$ under broad and narrow model, respectively). The detailed result of the nonparametric linkage analysis is shown in Table II.

\section{DISCUSSION}

Our result found maximum NPL scores of 3.33 $(P=0.0003)$ and $2.96(P=0.0008)$ at marker D15S976 under broad and narrow phenotype model, respectively. This finding attains the level of significance $\left(P<7 \times 10^{-4}\right)$ for suggestive linkage for sibling pair analysis [Lander and Kruglyak, 1995]. The NPL score 
TABLE II. Nonparametric Linkage Analysis in Narrow and Broad Disease Phenotypes for the Taiwanese Pedigrees, $\mathrm{n}=52$

\begin{tabular}{lccccc}
\hline & \multicolumn{2}{c}{ Narrow model } & & \multicolumn{2}{c}{ Broad model } \\
\cline { 2 - 3 } \cline { 5 - 6 } Markers & $\mathrm{Z}$ & $P$ value & $\mathrm{Z}$ & $P$ value & Information content \\
\hline D15S113 & 1.85 & 0.025 & 2.09 & 0.016 & 0.88 \\
D15S1043 & 1.54 & 0.052 & 1.90 & 0.027 & 0.82 \\
D15S165 & 1.97 & 0.018 & 2.50 & 0.005 & 0.78 \\
D15S976 & 2.96 & 0.0008 & 3.33 & 0.0003 & 0.85 \\
D15S1360 & 2.78 & 0.002 & 2.71 & 0.003 & 0.82 \\
D15S144 & 1.92 & 0.021 & 1.69 & 0.043 & 0.78 \\
\hline
\end{tabular}

of D15S1360, to which was reported significant linkage of P50 inhibition deficit in schizophrenia in the initial study [Freedman et al., 1997], is $2.71(P=0.003)$ and $2.78(P=0.002)$ under broad and narrow model, respectively. Our finding supports the results of the initial study because the $P$ value exceeds the threshold $(P<0.01)$ suggested for support of previously obtained significant linkage results [Lander and Kruglyak, 1995].

This study shows discrepant linkage result between parametric and nonparametric linkage analysis. Because parametric linkage analysis can be highly sensitive to misspecification of the linkage model [Clerget-Darpoux et al., 1986], it is error prone for analyses of complex disorders such as schizophrenia, for which the mode of inheritance is uncertain. Furthermore, our family sample containing primarily sibling pairs has limited power for LOD score analysis. The NPL analysis is robust to uncertainty about mode of inheritance, much more powerful and less prone to positive errors than other nonparametric methods, and nearly as powerful as LOD score analysis under the correct parametric model [Kruglyak et al., 1996]. Therefore, the positive result of NPL analysis in this study supports suggestive linkage evidence for linkage of schizophrenia to chromosome 15q13-14.

The present study found the peak NPL score at marker D15S976, $1 \mathrm{cM}$ centromeric to D15S1360, which was significant in the initial study [Freedman et al., 1997] and a follow-up study [Leonard et al., 1998]. These two previous studies did not genotype D15S976. Another study reported positive result at this marker (NPL score $=1.61 ; P=0.054$ ), though the peak NPL score was at D15S1360 (NPL score $=1.79$; $P=0.038)$ and at D15S1043 (NPL score $=1.81$; $P=0.037$ ), $2.5 \mathrm{cM}$ centromeric to D15S1360 [Riley et al., 2000]. Considering these positive results, the most promising region for a candidate gene for schizophrenia extends from D15S1043 to D15S1360.

Mapping of this region has revealed a number of expressed sequences that have not been fully characterized and several brain-expressed genes, of which CHRNA7 is the most promising candidate for schizophrenia. Several lines of neurobiological investigation have supported the role of the $\alpha-7$ nicotinic receptor in schizophrenia [Leonard et al., 1996]. CHRNA7 is now known to be partially duplicated (exon, 5-10) with four novel upstream exons. The duplication lies within $5 \mathrm{cM}$ of CHRNA7, and the duplicated sequence is expressed in the brain [Gault et al., 1998]. The partial duplication may have functional relevance and should be considered as a candidate.

Other known brain-expressed genes in this region, including tight junction protein 1 (TJP1) at $15 \mathrm{q} 13$ [Mohandas et al., 1995], cysteine knot superfamily 1, bone morphogenetic protein (BMP) antagonist 1 (CKTSF1B1) at 15q13-15 [Topol et al., 2000], and secretory granule neuroendocrine protein 1 (SGNE1) at 15q13-14 [Roebroek et al., 1989]. These might also be postulated as potential candidate genes accounting for the positive linkage signals in this study, though the function of some of these genes is still uncertain and their functional significance for schizophrenia is unknown.

The present study provides suggestive evidence for linkage of schizophrenia to loci at chromosome 15q1314 and replicates the initial linkage finding in an ethnically distinct sample. However, we remain cautious in our interpretation because suggestive linkage indicates statistical evidence expected to occur one time at random in a genome scan. Thus, a false positive result cannot be ruled out [Lander and Kruglyak, 1995]. Further replication studies in larger samples are warranted. Further determination of the role of the candidate gene in the chromosome region will require identification of the mutation that gives rise to the linkage signal and understanding of how its effects on neuronal function interact with other genetic and environmental factors to cause schizophrenia.

\section{REFERENCES}

American Psychiatric Association. 1994. Diagnostic and statistical manual, 4th ed, Washington DC: American Psychiatric Association.

Clerget-Darpoux F, Bonaiti-Pellie C, Hochez J. 1986. Effects of misspecifying genetic parameters in lod score analysis. Biometrics 42:393-399.

Cottingham RW Jr, Idury RM, Schaffer AA. 1993. Faster sequential genetic linkage computations. Am J Hum Genet 53:252-263.

Curtis L, Blouin JL, Radhakrishna U, Gehrig C, Lasseter VK, Wolyniec P, Nestadt G, Dombroski B, Kazazian HH, Pulver AE, Housman D, Bertrand D, Antonarakis SE. 1999. No evidence for linkage between schizophrenia and markers at chromosome 15q13-14. Am J Med Genet (Neuropsychiatr Genet) 88:109-112.

Freedman R, Coon H, Myles-Worsley M, Orr-Urtreger A, Olincy A, Davis A, Polymeropoulos M, Holik J, Hopkins J, Hoff M, Rosenthal J, Waldo MC, Reimherr F, Wender P, Yaw J, Young DA, Breese CR, Adams C, Patterson D, Adler LE, Kruglyak L, Leonard S, Byerley W. 1997. Linkage of a neurophysiological deficit in schizophrenia to a chromosome 15 locus. Proc Natl Acad Sci USA 94:587-592.

Gault J, Robinson M, Berger R, Drebing C, Logel J, Hopkins J, Moore T, Jacobs S, Meriwether J, Choi MJ, Kim EJ, Walton K, Buiting K, 
Davis A, Breese C, Freedman R, Leonard S. 1998. Genomic organization and partial duplication of the human $\alpha-7$ neuronal nicotinic acetylcholine receptor gene (CHRNA7). Genomics 52:173-185.

Hwu HG. 1999. Psychiatric diagnostic assessment. In: Hwu HG, editor. Manual of psychiatric diagnosis, 2nd ed. Taipei: Publication Committee, College of Medicine, National Taiwan University. p 7-42

Hwu HG, Yang SY. 1987. Psychiatric diagnostic assessment: establishment and inter-rater reliability. Chin Psychiatry 2:267-278.

Kaufmann CA, Suarez B, Malaspina D, Pepple J, Svrakic D, Markel PD, Meyer J, Zambuto CT, Schmitt K, Matise TC, Friedman JMH, Hampe C, Lee H, Shore D, Wynne D, Faraone SV, Tsuang MT, Cloninger CR. 1998. NIMH Genetics Initiative Millennium Schizophrenia Consortium: linkage analysis of African-American pedigrees. Am J Med Genet (Neuropsychiatr Genet) 81:282-289.

Kruglyak L, Daly MJ, Reeve-Daly MP, Lander ES. 1996. Parametric and non-parametric analysis: a unified multipoint approach. Am J Hum Genet 58:1347-1363.

Lahiri DK, Bye S, Nurnberger JI Jr, Hodes ME, Crisp M. 1992. A nonorganic and non-enzymatic extraction method gives higher yields of genomic DNA from whole-blood samples than do nine other methods tested. J Biochem Biophys Meth 25:193-205.

Lander E, Kruglyak L. 1995. Genetic dissection of complex traits: guidelines for interpreting and reporting linkage results. Nat Genet 11:241-247.

Lathrop GM, Lalouel JM, Julier C, Ott J. 1984. Strategies for mutilocus linkage analysis in humans. Proc Nat Acad Sci USA 81:34433446 .

Leonard S, Adams C, Breese CR, Adler LE, Bickford P, Byerley W, Coon H, Griffith JM, Miller C, Myles-Worsley M, Nagamoto HT, Rollins Y,
Stevens KE, Waldo M, Freedman R. 1996. Nicotinic receptor function in schizophrenia. Schizophr Bull 22:431-445.

Leonard S, Gault J, Moore T, Hopkins J, Robinson M, Olincy A, Adler LE, Cloninger R, Kaufmann CA, Tsuang MT, Faraone SV, Malaspina D, Svrakic DM, Freedman R. 1998. Further investigation of a chromosome 15 locus in schizophrenia: analysis of affected sibpairs from the NIMH Genetics Initiative. Am J Med Genet (Neuropsychiatr Genet) 81:308-312.

Mohandas TK, Chen XN, Rowe LB, Birkenmeier EH, Fanning AS, Anderson JM, Korenberg JR. 1995. Localization of the tight junction protein gene TJP1 to human chromosome 15q13, distal to the PraderWilli/Angelman region, and to mouse chromosome 7. Genomics 30:594597.

Neves-Pereira M, Bassett AS, Honer WG, Lang D, King NA, Kennedy JL. 1998. No evidence for linkage of the CHRNA7 gene region in Canadian schizophrenia families. Am J Med Genet (Neuropsychiatr Genet) 81:361-363.

Riley BP, Makoff A, Mogudi-Carter M, Jenkins T, Williamson R, Collier D, Murray R. 2000. Haplotype transmission disequilibrium and evidence for linkage of the CHRNA7 gene region to schizophrenia in Southern African Bantu families. Am J Med Genet (Neuropsychiatr Genet) 96:196-201.

Roebroek AJM, Dehaen MRM, van Bokhoven A, Martens GJM, Marynen P, van den Berghe H, Van de Ven WJM. 1989. Regional mapping of the human gene encoding the novel pituitary polypeptide 7B2 to chromosome 15q13-q14 by in situ hybridization. Cytogenet Cell Genet $50: 158-160$

Topol LZ, Modi WS, Koochekpour S, Blair DG. 2000. DRM/Gremlin (CKTSF1B1) maps to human chromosome 15 and is highly expressed in adult and fetal brain. Cytogenet Cell Genet 89:79-84. 